\title{
Microstructural and microchemical mechanisms controlling intergranular stress corrosion cracking in light-water-reactor systems
}

\author{
Stephen M. Bruemmer \\ Materials Sciences Department, Pacific Northwest Laboratory, Richland, WA 99352, USA \\ Gary S. Was \\ Departments of Nuclear Engineering and Materials Science and Engineering, University of Michigan, Ann Arbor, MI 48109, USA
}

\begin{abstract}
This review paper examines mechanisms controlling IGSCC in selected LWR components. Emphasis is placed on identifying material microstructures and microchemistries which promote susceptibility to premature failure. Two important examples are evaluated in some detail: stainless steel pipe cracking and primary-side SCC of alloy 600 steam generator tubing. In each case, grain boundary segregation and precipitation phenomena in these materials are reviewed and assessed relative to the mechanisms of IGSCC. This paper summarizes materials presented at the 1993 International Summer School on the Fundamentals of Radiation Damage held at the University of Illinois. A more comprehensive overview of SCC mechanisms and LWR examples was provided at the school, but will not be included in this article. Microstructural and microchemical aspects controlling IGSCC described here serve as a lead-in to the following paper focussing on how irradiation influences SCC resistance of reactor core components.
\end{abstract}

\section{Introduction}

Material degradation has been a continuing problem in commercial light-water-reactor (LWR) nuclear power plants. Although several other sources of degradation exist, corrosion remains a dominant issue related to plant availability, economics and reliability. Localized corrosion, and intergranular stress corrosion cracking (IGSCC) in particular, has prompted severe consequences as illustrated by the impact of welded stainless steel pipe cracking in boiling-water reactors (BWRs) and steam generator tube failures in pressurized water reactors (PWRs). For example, IGSCC of recirculation system piping led to significant reductions in US reactor operation in the mid-1980s, reaching a maxinum capacity loss of about $15 \%$ in 1984 . Documented observations of BWR pipe cracking exceed 1000 cases with an estimated cost for US utilities of more than 3 billion dollars [1]. While incidents of pipe IGSCC have greatly decreased over the last 10 years due to remedial actions, steam generator tube IGSCC failures have increased. Tube problems may force most US PWRs to replace their existing steam generators well before its design life of 40 years is achieved [2]. Methods to mitigate either primary-side or secondaryside IGSCC in generator tubing are not well established. This is a direct consequence of the current poor understanding of the mechanisms controlling tube degradation. Many other components have experienced SCC within LWR systems including steam turbine materials, reactor core internals, jet pump beams and feedwater nozzles. Fortunately, none of these problems have impacted plant operation to the same degree.

\section{Pipe cracking of austenitic stainless steels}

BWR pipe cracking was first observed in small diameter $(<25 \mathrm{~cm})$ recirculation lines nearly 30 years 
ago, but did not become a significant concern until 1974. [3] IG cracks were detected in the heat-affected zone (HAZ) of high-carbon ( $\geq 0.05 \mathrm{wt} \%) 304$ stainless steel pipe weldments. A few years later, cracking was also detected in the more critical large diameter $(>60$ $\mathrm{cm}$ ) recirculation systems. Replacement of these lines was considerably more difficult and costly. As a result, a wide range of basic and applied research activities were initiated to develop a mechanistic understanding of the IGSCC process and, more importantly, identify remedial actions to improve behavior of existing components as well as new corrective measures to ensure cracking resistance for new piping systems. For the most part these research activities were highly successful [3]. IGSCC of stainless steel piping is probably the best understood environmental cracking process and serves as a basis for much of our general understanding of IGSCC phenomena.

The conditions necessary to promote IGSCC are a susceptible material microstructure, a sufficiently corrosive environment, and the presence of tensile stresses. For BWR piping these conditions can be described more specifically as: (1) grain boundary chromium depletion (sensitized microstructure), (2) oxygenated ( $>$ $15 \mathrm{ppb}$ ) high-temperature water, and (3) applied plus residual tensile stresses approaching the steel yield stress. The following sections overview the basic metallurgy of stainless steels with reference to the development of an IGSCC-susceptible microstructure. Much of the presented information is based on a recent review by Bruemmer. [4]

\section{Intergranular precipitation}

A large number of different second phases can form in the $\mathbf{3 0 0}$ series SSs including carbides, nitrides and various intermetallics. The dominant carbide is the fcc $\mathrm{M}_{23} \mathrm{C}_{6}$ with chromium as the primary $(\sim 65$ at\% $)$ metallic component [5]. Precipitation of the carbide is a function of thermal treatment and bulk composition (primarily carbon) of the heat. A typical method of illustrating precipitation behavior is by a time-temperature precipitation (TTP) diagram as shown in Fig. 1. Carbide nucleation and growth occurs first at the interface between delta ferrite and austenite, followed by precipitation at austenite grain boundaries, incoherent twin boundaries and finally, at coherent twins. The trends shown in Fig. 1 for a 304 SS also have been demonstrated for $316 \mathrm{SS}$, duplex alloys and high-chromium stainless steels. Delta ferrite will not be present in all alloys, but is possible in many "austenitic" SSs depending on bulk composition and processing treatment. Carbon is an extremely effective austenite stabilizer, and its content is a critical factor in determining whether ferrite will remain in 304 and 316 SSs.

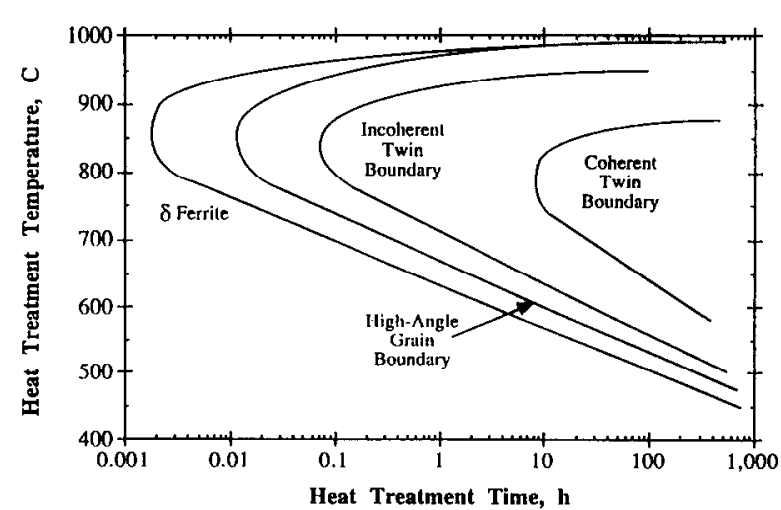

Fig. 1. Time-temperature-precipitation curves for $M_{23} C_{6}$ second phase to various internal interfaces for a $304 \mathrm{SS}$, based on results from Ref. [6].

Carbide precipitation occurs readily in SSs due to the low solid solubility of carbon. Cooling from high temperature will trap an excess or supersaturated amount of carbon which can then precipitate during lower temperature aging. Carbon solubility depends on bulk composition and relatively consistent predictions can be made using empirical relationships determined for a particular type of SS as a function of heat treatment temperature. The solubility limit is exceeded in a $0.08 \mathrm{wt} \% \mathrm{C}, \mathrm{Fe}-18 \mathrm{Cr}-8 \mathrm{Ni}$ alloy at $\sim 980^{\circ} \mathrm{C}$, while in a $0.02 \mathrm{wt} \% \mathrm{C}$ alloy limits are $\sim 820^{\circ} \mathrm{C}$. Carbide precipitation is favored at temperatures below these values.

The morphology, density and distribution of the intergranular $\mathrm{M}_{23} \mathrm{C}_{6}$ precipitates depend on grain boundary misorientation and structure. Carbide morphologies can be classified as two-dimensional "sheets," as dendrites which are initially lamellar or as small geometric particles. Geometric carbides are common resulting from precipitates nucleating at grain boundaries and growing preferentially into one grain. A crystallographic orientational relationship is established with the matrix to minimize interfacial energy. Carbides nucleate on high energy sites in the grain boundary, probably at ledges or sites of ledge annihilation.

Another intergranular precipitate that can form in nitrogen- and nuclear-grade SSs is chromium nitride, $\mathrm{Cr}_{2} \mathrm{~N}$. Both type $304 \mathrm{LN}$ and $316 \mathrm{LN}$ will exhibit significant nitride precipitation after heat treatments in the 550 to $750^{\circ} \mathrm{C}$ temperature range. Nitrides can also form in the nuclear-grade heats since bulk nitrogen levels can be up to $0.1 \mathrm{wt} \%$. However, bulk nitrogen levels need to be quite high ( $>0.15 \mathrm{wt} \%$ ) to promote significant nitride precipitation after practical heat treatments.

Various intermetallic phases can form after long thermal exposures in type 316 SS. Sigma $(\sigma)$ and chi 
$(\chi)$ phases nucleate and grow at high energy interfaces such as high-angle grain boundaries and incoherent interphase boundaries. Both intermetallics are $\mathrm{Fe}-\mathrm{Cr}-$ Mo compounds with the tetragonal $\sigma$ phase having a higher concentration of chromium and lower molybdenum than the bcc $\chi$ phase. It is important to note that these intermetallic phases typically require many hours at high temperatures $\left(700-850^{\circ} \mathrm{C}\right)$ to nucleate.

Martensite also forms in unstabilized SSs under certain conditions. At moderate levels of plastic deformation (i.e., cold work), the planar dislocation structures typical of this low stacking fault energy alloy evolves into cell structures which can contain eta martensite. With increasing deformation, alpha martensite forms at eta intersections and becomes quite significant at higher strains. Temperature, extent of deformation and bulk material composition all influence the amount of martensite that will form.

The martensite formation temperature $\left(M_{\mathrm{s}}\right)$ is a function of the SS composition with carbon, nitrogen and nickel having the largest effect. A typical 304 SS alloy would be expected to have a transformation temperature of about $-150^{\circ} \mathrm{C}$. However, in low-carbon SSs, the $M_{\mathrm{s}}$ temperature can rise above room temperature. Martensite nucleation has been documented at grain boundaries in sensitized SSs, perhaps due to local composition differences and deformation characteristics.

\section{Intergranular chromium depletion}

The precipitation of chromium-rich $\mathrm{M}_{23} \mathrm{C}_{6}$ carbides on grain boundaries promotes the development of an adjacent region depleted in chromium. Depletion is controlled by the thermodynamics of carbide formation and differences between the diffusivities of chromium and carbon. It occurs in a temperature range where carbides are thermodynamically stable and chromium diffusion is sufficiently rapid for carbide nucleation and growth in a finite time frame. This process is commonly referred to as sensitization, although this term is also used to indicate intergranular corrosion susceptibility (often incorrectly).

The formation of a grain boundary chromium depleted region in stainless alloys was inferred many years ago [7], but was not directly established until the last 15 years. Analytical transmission electron microscopy (ATEM) has enabled chromium depletion profiles to be measured in various materials and as a function of thermal and thermomechanical treatment. The best developed and most used ATEM approach has implemented a scanning transmission electron microscope (STEM) with an energy dispersive $\mathrm{X}$-ray spectrometer (EDS). Instruments with the capability are now in widespread use and a large number of investigators (see Ref. [4]) have reported chromium depletion measurements. Examples of such measurements for radiation-induced chromium depletion are included in the paper of Kenik in this volume.

An example of heat treatment effects on chromium depletion is shown in Fig. 2 for a high-carbon 304 SS in (a) and for a high-carbon alloy $600(\mathrm{Ni}-18 \mathrm{Cr}-7 \mathrm{Fe})$ heat in (b). The width of the chromium-depleted zone increases with heat treatment time at $700^{\circ} \mathrm{C}$. for both materials. For the 304SS, the total width changes from about $50 \mathrm{~nm}$ after $1 \mathrm{~h}$, to $100 \mathrm{~nm}$ after $10 \mathrm{~h}$, and finally to $500 \mathrm{~nm}$ after $100 \mathrm{~h}$. Minimum chromium concentrations appear to decrease (from 12.5 to $11.4 \mathrm{wt} \%$ ), then increase (to $>12 \mathrm{wt} \%$ ) with heat treatment time. The initial decrease reflects the resolution limitations $(\sim 5$ $\mathrm{nm}$ ) for microchemical analysis using this particular STEM-EDS, i.e., the profile is simply to narrow to accurately determine the interfacial chromium concentration. Interfacial chromium concentrations will discernably increase after long times due to a bulk reduc-
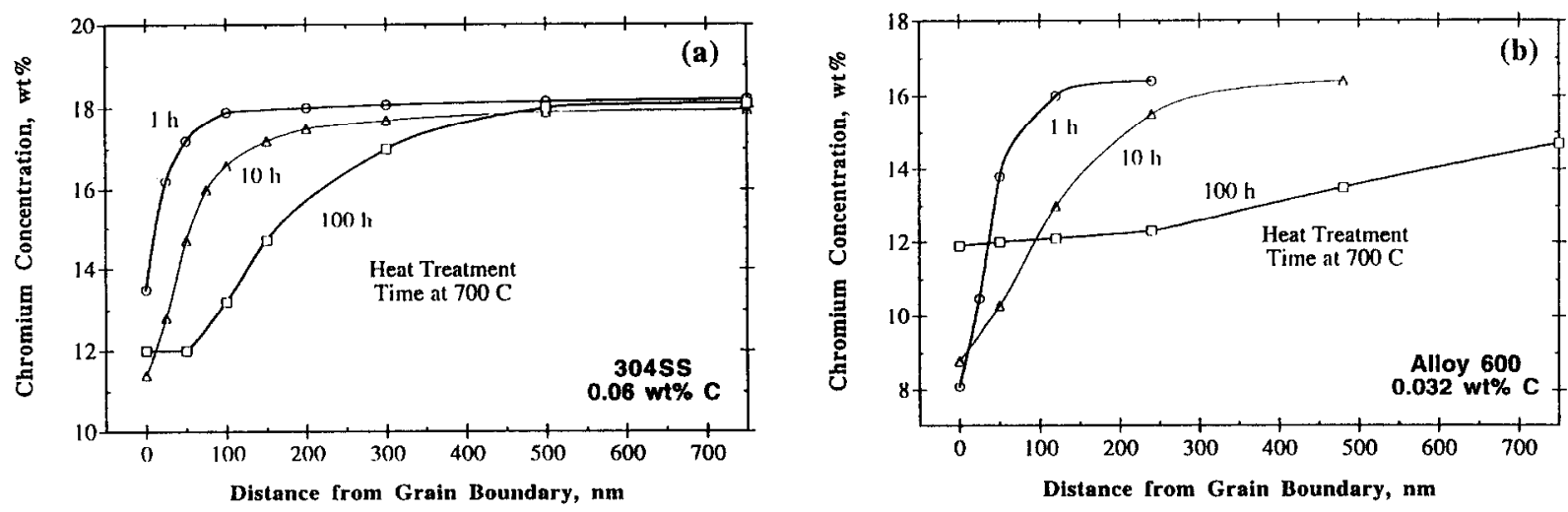

Fig. 2. Heat treatment effects on chromium depletion profiles in 304 SS (a) and alloy 600 (b). 


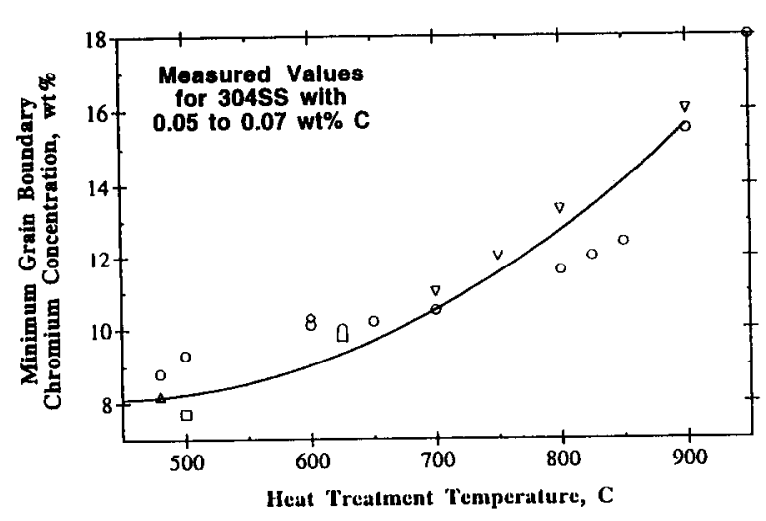

Fig. 3. Minimum grain boundary chromium concentrations measured in $304 \mathrm{SSs}$ over a range of heat-treatment temperatures.

tion in carbon content and a decreased thermodynamic driving force for continued carbide growth. The behavior of the nickel-base stainless alloy will be discussed in a later section.

Chromium concentrations at the carbide interface decrease as the heat treatment temperature is decreased due to temperature effects on carbon and chromium activities. This relationship is illustrated in Fig. 3 and incorporates measured chromium minimums in high-carbon 304SS from several sources. Minimums drop from near bulk concentrations $(18 \mathrm{wt} \%)$ at $900^{\circ} \mathrm{C}$ to about $8 \mathrm{wt} \%$ at $500^{\circ} \mathrm{C}$. The second aspect of critical importance to characterize chromium depletion is the width of depleted zone. As indicated in Fig. 2, the depletion width increases with time after intergranular carbides are nucleated. Interfacial chromium minimum also tend to increase with increase in depletion width due to desensitization. As a result, the volume of the grain boundary depleted zone is not increasing at the same rate as the depletion width. Each of these variables will be correlated to environmental degradation in a following section.

Carbide precipitation and depletion characteristics after thermal or thermomechanical exposure can vary significantly from one grain boundary to another and even along an individual boundary length. Much of this variability results from differences in grain boundary energies. High-energy interfaces exhibit early carbide nucleation and may develop a semicontinuous distribution of carbides before nucleation occurs at low-energy interfaces. Even though grain boundary diffusion is much more rapid than bulk diffusion, differences in chromium depletion have been observed along a boundary with well-spaced carbides and can be caused by localized interfacial migration. These microchemical complications are present after all heat treatments, but their magnitude depends on the specific exposure.

\section{Equilibrium impurity segregation}

Impurity elements present at low levels in austenitic SSs can reach high levels at grain boundaries due to equilibrium segregation. Although the number of direct measurements of grain boundary composition have been limited, several elements including phosphorus, sulfur, nitrogen, boron and silicon segregate under specific conditions. The most consistently measured impurity segregant in $\mathrm{Fe}$ - and Ni-base stainless alloys has been phosphorus. The temperature dependence of segregation is shown in Fig. 4 with equilibrium levels decreasing with increasing heat treatment temperature. Grain boundary phosphorus contents up to $\sim 30$ at $\%$ have been measured in 304 SS with a grain boundary enrichment ratio of more than 1300 [8]. Segregation kinetics become much more rapid as the heat treatment temperature is increased, and equilibrium levels are reached in much shorter times. Typical bulk phosphorus levels $(100 \mathrm{ppm})$ in commercial steels can produce significant intergranular enrichments. Thus, materials in the "sensitized" condition will most likely have considerable phosphorus segregation along with $\mathrm{M}_{23} \mathrm{C}_{6}$ carbides and chromium depletion defining the local microchemistry.

The kinetics of phosphorus segregation in type $\mathbf{3 1 6}$ SS are slower than type 304 particularly at temperatures below about $700^{\circ} \mathrm{C}$. Molybdenum additions in type 316 SS promote an increased equilibrium segregation, but a significant decrease in kinetics. These differences in segregation between type 304 and 316 SS are very similar to differences observed for chromium depletion. Heat treatment temperatures which induce significant phosphorus enrichment (i.e., $600-650^{\circ} \mathrm{C}$ for 304 and $700-750^{\circ} \mathrm{C}$ for 316$)$ are also those which promote rapid sensitization.

Segregation of other impurity elements to stainless steel grain boundaries has been observed, but often

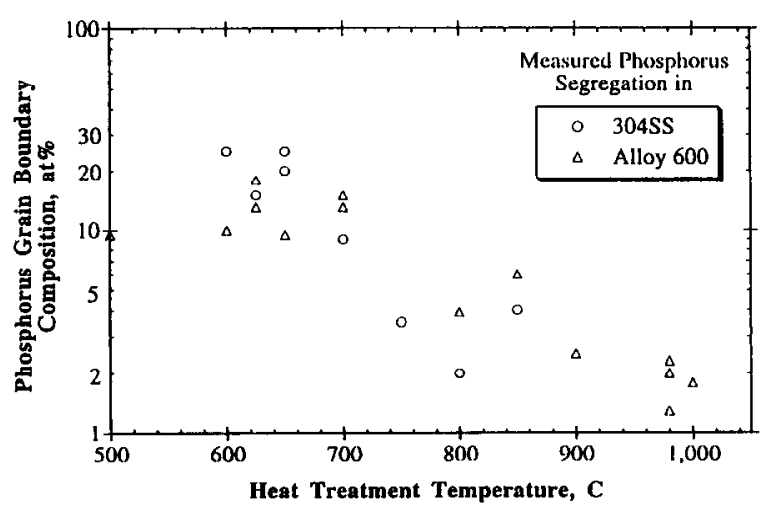

Fig. 4. Measured grain boundary phosphorus segregation in $304 \mathrm{SS}$ and alloy 600 as a function of heat-treatment temperature. 
requires high bulk contents or special thermal treatments. Sulfur segregates rapidly to boundaries if preexisting sulfides (e.g., $\mathrm{MnS}$ and $\mathrm{CrS}$ ) are dissolved by a high-temperature $\left(>1200^{\circ} \mathrm{C}\right)$ exposure. Without such treatment, grain boundary sulfur segregation is very slight even in doped alloys. However, sulfide precipitates have been identified on intergranular fracture surfaces. This behavior for sulfur in stainless steel results from the effectiveness of certain alloying additions (i.e., $\mathrm{Mn}$ ) in precipitating sulfur out of solid solution. As a result, the amount of free sulfur available to segregate is typically extremely small and insufficient to promote significant grain boundary segregation.

Nitrogen additions to austenitic SSs have received considerable interest as a replacement strengthening element for carbon. Like carbon, nitrogen segregates to and can precipitate (i.e., $\mathrm{Cr}_{2} \mathrm{~N}$ ) at grain boundaries. Briant [9] has documented significant nitrogen enrichment at grain boundaries after heat treatments between 600 and $700^{\circ} \mathrm{C}$. It appears that high-nitrogen heats (e.g., $\mathbf{N}$ grades) will show considerable nitrogen segregation and eventually chromium nitride precipitation. Grain boundary segregation of nitrogen in 304 and 316 grades is also likely since bulk nitrogen levels are typically greater than $0.02 \mathrm{wt} \%$. However, segregation behavior in these materials has not been reported.

Several other alloying and impurity elements have been observed to enrich boundaries in stainless steels due to equilibrium, and often nonequilibrium, processes. Boron can strongly segregate as a result of either process, but most observations result from a vacancy-drag mechanism after steels are quenched from a high temperature. [10] Primary alloying elements such as chromium and molybdenum also have been shown to segregate in specific alloys reaching relatively small levels of enrichment. [11] Finally, silicon has been identified at grain boundaries in a Type 304SS by Joshi and Stein. [12] However, silicon segregation by equilibrium processes appears to be very small (enrichment ratio probably $<2$ ). Quite different behavior is observed for many of these elements during irradiation exposure. This nonequilibrium segregation will be discussed in the following paper.

\section{Grain boundary electrochemistry and intergranular corrosion}

Grain boundary microchemistry in a sensitized austenitic SS can be rather complex as described in a previous section. While the matrix remains at about its initial composition (except for carbon), grain boundary regions exhibit $\mathrm{M}_{23} \mathrm{C}_{6}$ carbides, a chromium-depleted zone which extends some distance from the boundary and potentially impurity (e.g., phosphorus) enrichment

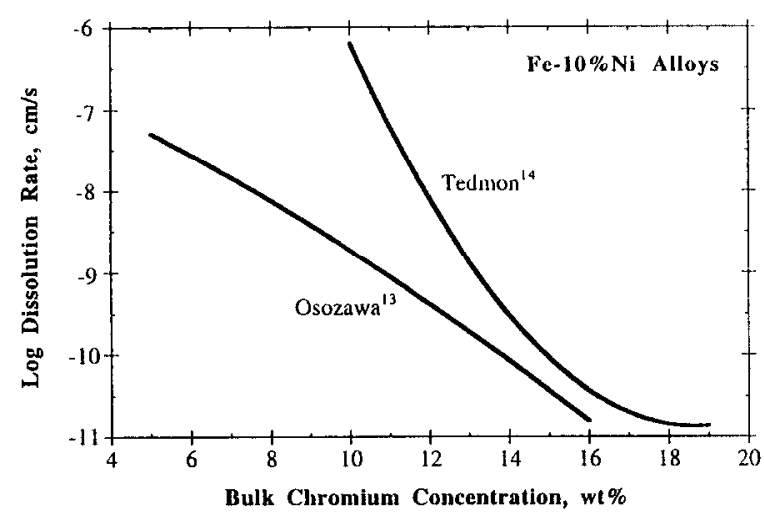

Fig. 5. Bulk chromium concentration effects on dissolution rates for $\mathrm{Fe}-10 \% \mathrm{Ni}$ alloys.

at the interface. Thus, four distinct chemistries may exist in sensitized SS. Each can affect the electrochemical response of the material, thereby impacting intergranular corrosion and SCC susceptibility. In most cases, the chromium depleted zone dominates due to its effect on material electrochemistry. The variation in chromium concentration from 16 to $18 \%$ for most of the material to as low as $8 \%$ near grain boundaries creates a situation where localized attack can occur.

Stainless alloys obtain their corrosion resistance by the presence of chromium. For ternary alloys of ironnickel-chromium, levels of about $12 \%$ or more chromium prompt a significant improvement in general corrosion resistance as indicated in Fig. 5. [13,14] The current density (i.e., corrosion rate) sharply drops in the "passive" region of the polarization curve with increasing bulk chromium content. Chromium additions lead to a reduction in the rate of dissolution in both this passive region and in the "active" potential region at lower potentials. At the same time, the potential range over which the material is passive increases and the active range decreases.

These characteristics of electrochemical polarization behavior indicate critical thermodynamic and kinetic aspects defining a materials corrosion resistance. The passive range shows the thermodynamic stability region for protective oxide film formation, while current densities define the kinetics of continuing metal dissolution. Chromium has a strong effect because it incorporates into the film making it more protective. Enrichment of chromium in the $\mathrm{M}_{2} \mathrm{O}_{3}$ film increases with bulk chromium concentration, reaching a rather high metal fraction. A sensitized material can contain a continuous path of low-chromium, less-passive material which may be susceptible to attack. Such a localized region of active behavior surrounded by a passive matrix can lead to high rates of dissolution. Potentials of 
this magnitude, near the active-passive transition, have been shown to promote IGSCC in many environments including BWR water [15-23].

Electrochemistry of chromium-depleted grain boundaries has been inferred from studies on bulk alloys with compositions representing those typical of boundary regions $[13,14,24-26]$. All of these investigations reach a similar conclusion as noted above, dissolution rates of chromium-depleted composition are expected to be much larger than for the matrix. Attempts have also been made to isolate electrochemical response from grain boundary regions in sensitized and nonsensitized materials [27-29]. Results were qualitatively consistent with bulk alloy measurements in that depleted grain boundary regions showed higher dissolution rates.

Few direct correlations between measured grain boundary chromium depletion and intergranular corrosion have been reported. Bruemmer et al. [30] have documented the most detailed comparison between chromium depletion and intergranular corrosion. Type 304 and 316SSs were heat treated, their depletion profiles characterized by ATEM and corrosion response investigated using the electrochemical potentokinetic reactivation (EPR) test. Correlations were made between EPR and specific aspects of the depletion profile, i.e., minimum grain boundary chromium contents, depletion widths and depletion volumes. Critical chromium minimums for attack were found to be about $13 \mathrm{wt} \%$ and the best correlation was observed between EPR and depletion volume below $13.5 \mathrm{wt} \%$ (Fig. 6). This study and others have documented that chromium depletion is the dominant microchemical component controlling intergranular attack under these environmental (active-passive potential regime) conditions.

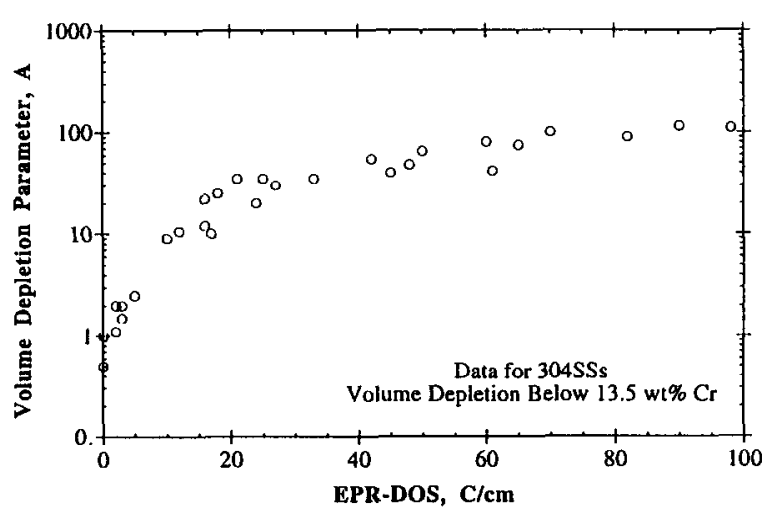

Fig. 6. Dependence of IG corrosion susceptibility as indicated by the EPR test on the extent of grain boundary chromium depletion described by the volume depletion [30].
Other elements besides chromium have an effect on the passivation characteristics of SSs. Molybdenum is the most important of these for the common alloys. Additions of $0.5 \%$ or more molybdenum lowers active and passive current densities and improves corrosion resistance [5]. It can directly impact depassivation/repassivation of the film which controls pitting attack and SCC. Molybdenum does not appear to incorporate into the protective film as does chromium, but has been observed to enrich metal surfaces $[31,32]$. Depletion of molybdenum also occurs during sensitization of 316 SS and further degrades localized corrosion resistance. The importance of molybdenum depletion on intergranular corrosion has been demonstrated by Briant and Hall [33]. Depletion characteristics in 316 SS must consider both chromium and molybdenum to predict corrosion behavior.

Grain boundary reactivity in corrosive environments can also be influenced by the presence and compositions of precipitates and by solute segregation. Electrochemical behavior of second-phase precipitates at grain boundaries has not been extensively studied. It has been generally observed that the dissolution rate of $\mathrm{M}_{23} \mathrm{C}_{6}$-type carbides is quite low, but increases as iron replaces chromium in the carbide. Chromium-rich carbides in sensitized stainless steels are not attacked in many solutions even though the depleted region is aggressively dissolved. These carbides are most likely cathodic to the low chromium region and accelerate dissolution of the depleted zone.

Grain boundary segregation of impurity elements, such as phosphorus and sulfur, is known to promote IG corrosion and SCC in many iron and nickel-base alloys. In stainless alloys, phosphorus segregation appears to dominate because of its relatively high impurity level. Phosphorus enrichment at grain interfaces promotes attack in highly oxidizing environments, e.g., boiling nitric acid. IG corrosion is not observed in less oxidizing solutions where chromium depleted material is aggressively attacked, such as BWR water. Phosphorus appears to be detrimental at transpassive potentials. However, it may influence attack at active-passive potentials if present along with chromium depletion. Thus, the presence of second phase and segregants at grain boundaries must be considered to assess the overall effect of interfacial microchemistry

\section{Intergranular stress corrosion cracking}

As was the case for IG corrosion, chromium depletion is the dominant factor controlling IGSCC in austenitic stainless alloys. In slightly oxidizing environments such as BWR water and low-temperature acids, chromium depletion can induce IG cracking and lowductility failure. Stainless steel pipe weldments, where 


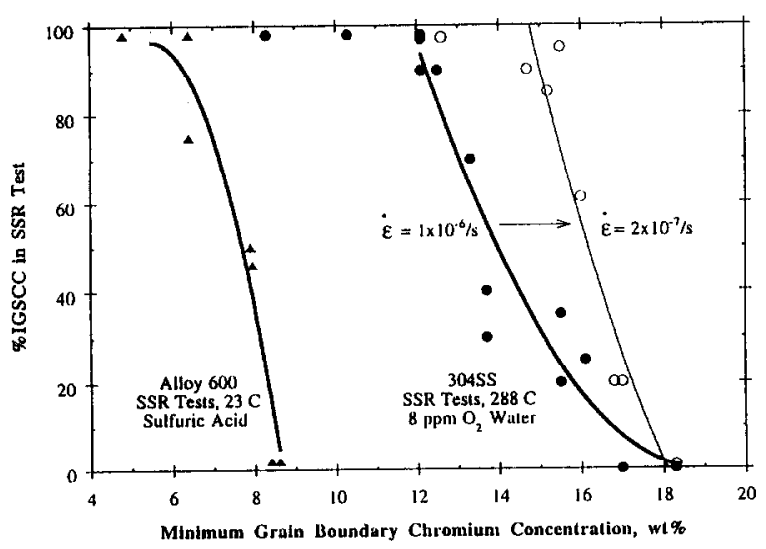

Fig. 7. Correlations between grain boundary chromium concentrations and IGSCC for 304 SS and alloy 600.

the weld-induced HAZ thermomechanical history promotes carbide precipitation and chromium depletion are particularly susceptible since a tensile residual stress distribution is also typically created which drives crack initiation and growth.

There have been many indirect relationships documented between chromium depletion and IGSCC, but few direct correlations. Bruemmer [34] found that the IGSCC of type 304 SS in oxygenated, high-temperature water was controlled by the grain boundary chromium concentration. Intergranular cracking was initiated in slow-strain-rate tests when local chromium levels dropped below a threshold level as shown in Fig. 7. Cracking severity and ductility loss increased as the boundary chromium content decreased. The threshold concentration to promote IGSCC is a function of the test strain rate and, at low deformation rates, only minor levels of chromium depletion ( 1 to $2 \mathrm{wt} \%)$ at boundaries are required for IG cracking. Was and Rajan [35] also mapped the onset of IGSCC in a low-temperature acidic solution for a nickel-base stainless alloy 600. Cracking was observed when grain boundary chromium levels dropped below $\sim 8 \mathrm{wt} \%$ as shown in Fig. 7.

The correlations presented in Fig. 7 point out the critical importance of chromium depletion, and chromium minimums in particular, on IGSCC of austenitic stainless alloys. The reference to "minimum" chromium contents should be noted, since the "average" grain boundary chromium content will be somewhat higher. Average depletion levels might be expected to control the extent of IG cracking. This concept of an average grain boundary microchemistry is important because a continuous path of susceptible material must be available for crack propagation. Such a continuous path is typically not present when the degree of sensitization is low $\left(<5 \mathrm{C} / \mathrm{cm}^{2}\right.$ as measured by the EPR test). Short isothermal or continuous cooling thermal treatments can promote isolated regions of carbide precipitation and chromium depletion. As a result, IGSCC may not occur in practical situations even though some grain boundaries exhibit low minimum contents. Estimates from percolation theory [36] suggest that 20 to $25 \%$ of grain boundaries need to be depleted below the threshold chromium concentration for IGSCC to occur. Relationships between IGSCC and grain boundary chemistry will always depend on many other critical factors including mechanical loading characteristics and environmental conditions as well as secondary material variables.

Grain boundary impurity segregation can promote IGSCC and hydrogen induced cracking (HIC) in many iron- and nickel-base alloys. Phosphorus segregation has been implicated in the IGSCC for low-carbon stainless steel heats [37] and in irradiation-assisted (IA) SCC $[38,39]$. However, evidence for such an effect for austenitic SSs in high-temperature water has not been reported. Impurity segregation was found to have only a small effect on crack-growth rates by Andresen and Briant [40]. Although, phosphorus, nitrogen and sulfur were enriched at grain boundaries in different SS specimens, only sulfur appeared to promote IG cracking. Sulfur was reported to be present as sulfides and in elemental form at boundaries. Cracking observed in the high-sulfur SSs was compared to similar results by Andresen [41] for environmental cracking of Inconel 182 weld metal.

The lack of a significant effect of impurity segregation on IGSCC of SSs reflects both the dominant effect of chromium depletion and the limited amount of controlled testing that has been performed. Phosphorus may promote IGSCC in more oxidizing environments as it does when segregated to boundaries in nickel. [42] Electrochemical potentials near the passive-transpassive transition were required, much higher than those typically present in service environments such as oxygenated high-temperature water. It is interesting to note that neutron and gamma radiation have a large effect on water chemistry and may shift SS electrochemical potentials to more oxidizing values (i.e., closer to passive-transpassive potentials). Thus, impurity segregation may still play a role in IGSCC under such conditions.

Other grain boundary microchemical and microstructural components have not been observed to play a major role in IGSCC. The presence of carbides will affect the local grain boundary electrochemical and deformation characteristics, and perhaps cracking susceptibility in certain environments. However, no direct link between carbides and cracking has been established for SSs. Martensite, if formed preferentially along grain boundaries can prompt environmental cracking [43-46]. Anodic dissolution or hydrogen 
embrittlement of this relatively brittle phase could result in rapid crack growth. The main question that remains is to what extent does preferential martensite form in practical circumstances. Considerable deformation occurs in the HAZ region during welding and within the plastic zone ahead of the propagating crack. Whether this deformation induces significant martensitic formation has not been established. Martensite effects appear to be small compared to the dominant effect of chromium depletion. It is essential to keep in mind that IGSCC does occur in cold-worked or creviced SSs without any grain boundary chromium depletion. Therefore, secondary microstructural and microchemical features may play a critical role in cracking under such conditions.

\section{Microchemistry, IGSCC and remedial actions}

Clearly grain boundary chromium depletion is the dominant material variable promoting IGSCC of austenitic SSs piping. Cracking susceptibility is a direct function of the interfacial chromium concentration, i.e. the degree of sensitization. For specific alloys, and for specific mechanical loading and environmental conditions, threshold grain boundary chemistries for IGSCC. can be identified. The production and fabrication of more resistant SS weldments depends on such understanding. Detrimental microchemistries can be avoided by modifying bulk composition and HAZ thermomechanical history. Remedial actions can also be applied to create a resistant microchemistry and improve material performance. This has been done for BWR piping by post-welding solution annealing (and rapid quenching) or by replacing the high-carbon SSs with nuclear grade steels with a maximum carbon level of $0.02 \mathrm{wt} \%$. The low-carbon content limits carbide precipitation, and thereby chromium depletion, under normal welding conditions. IGSCC can also be mitigated by protecting the susceptible HAZ by a corrosion-resistant cladding (e.g., 308L with ferrite levels $>8 \%$ ), or by a weld overlay to structurally reinforce the degraded weldment region. The weld overlay has been a cost-effective, temporary solution to repair existing cracked pipes. Current BWR practice is to apply more than simply a material remedy to improve piping SCC resistance [3]. In most cases, modifications to the residual tensile stress (by heat-sink welding, induction heating stress improvement or last-pass, heat-sink welding) and/or to the environment aggressiveness (ensure very high water purity and reduce oxygen content in solution by hydrogen additions) are applied. The use of multiple countermeasures is expected to minimize observations of pipe cracking and its effect on plant availability.

\section{Steam generator tube cracking: nickel-base alloy 600}

IGSCC on both the primary- and secondary-sides of PWR steam generator tubing has been a continuing problem for over 15 years. Recent data [47] shows that of the steam generator tubes plugged due to leakage, $31 \%$ were plugged due to primary side IGSCC and $44 \%$ were plugged due to secondary side IGSCC. Although both locations impact plant availability, primary-side SCC has raised the greatest concern in recent years [48] and remains the greatest mystery, and as such, will constitute the emphasis of this discussion. Cracking occurs in high-purity water in cold-worked material at locations of high stress such as roll transitions or U-bends. Temperature has a large influence on crack initiation roughly following an Arrhenius dependence. Primary-side SCC has not been observed at temperatures below $\sim 250^{\circ} \mathrm{C}$ and is most prevalent in hot-leg tubes $\left(>300^{\circ} \mathrm{C}\right)$. The water environment is also believed to be a critical factor, but the specific elements of the environment have not been identified.

A great many unknowns still exist concerning the mechanisms controlling primary-side IGSCC. Unlike the case of BWR pipe cracking, the basic processes controlling IGSCC are not well established. However, any proposed mechanism must involve the microstructure, microchemistry and mechanical properties of grain boundaries. To facilitate basic understanding, specific aspects of alloy 600 metallurgy are reviewed and discussed in the following sections based on recent papers by Bruemmer [49] and Was [50]. Interfacial carbide precipitation, chromium depletion, impurity segregation and local deformation characteristics are examined and related to IGSCC behavior.

\section{Carbide precipitation}

Chromium carbide precipitation occurs readily in alloy 600 because the carbon solubility is low even at very high temperatures, e.g., $0.03 \mathrm{wt} \%$ at $1000^{\circ} \mathrm{C}$. Precipitates in alloy 600 include $M_{7} C_{3}$ and $M_{23} C_{6}$ carbides as well as titanium nitrides and carbonitrides. The predominant precipitate formed during processing treatments and subsequent thermal treatment is the $\mathrm{M}_{7} \mathrm{C}_{3}(\mathrm{M}>95 \% \mathrm{Cr})$ carbide. These carbides have what is described as a pseudo-hexagonal structure. At higher aging temperatures or at longer times at lower temperatures when the carbon activity is lower, $\mathrm{M}_{23} \mathrm{C}_{6}$ can precipitate. This dendritic carbide has a cube-oncube relationship with the matrix, and has a metallic content of better than $90 \%$ chromium [51,52]. Grain boundary precipitates can be produced ranging from small (or large) discrete particles to a semi-continuous array of particles.

The low carbon solubility and the resulting high 
driving force for precipitation help explain the significant heat-to-heat variations in mill-annealed tubing microstructures and SCC resistance that have been observed. Carbide distributions can vary from predominately IG to predominately transgranular (TG) among heats within a given steam generator. These variations result from differences in bulk composition ( $C$ content) and thermomechanical history during processing and fabrication. Carbide precipitation in mill-annealed material is somewhat different from that in solution annealed and thermally treated material because of the interplay between deformation and annealing. Because of the varying carbon content, heat treatment and deformation schedules, the "mill-annealed" condition is very ill-defined with respect to microstructure. Although this carries over into the description of carbides, some generalizations can be made. Mill annealed material is generally characterized by a higher density of carbides in the matrix [51,53,54]. Some millannealed structures have predominantly intragranular carbides with only very sparse precipitation occuring on the grain boundaries. The principal carbide structure is again, $\mathrm{M}_{7} \mathrm{C}_{3}$ with $\mathrm{M}_{23} \mathrm{C}_{6}$ occuring only sporadically in the boundary and matrix. Because a significant amount of carbon has been precipitated during the mill anneal, the response to subsequent aging treatments is different from that of solution-annealed samples. Heat treatment following a mill-anneal results in significant carbide nucleation and growth along grain boundaries and in the matrix. The carbides nucleate along the grain boundary in regions between existing carbides, along carbide-matrix interfaces and along dislocations in the matrix [51]. The grain boundary carbides in this structure are much more discrete as opposed to the semi-continuous structure of carbides formed by thermal treatment following a solution anneal.

The final processing temperature plays a critical role in the amount of carbide precipitation that occurs during cooling and the amount of carbon remaining in solution. A high-temperature anneal $\left(>1000^{\circ} \mathrm{C}\right)$ tends to put more carbon into solution, produce a higher density of intergranular precipitates and is more resistant to SCC. Mill-processing conditions also have an important effect on microstructures of thermally treated tubing, i.e. secondary heat treatment at lower temperatures $\left(620\right.$ to $\left.700^{\circ} \mathrm{C}\right)$. The ability to produce a favorable microstructure depends on the carbon remaining in solution which is available to precipitate. A low-temperature mill anneal and a slow-cooling rate may result in a high density of intragranular precipitates and an insufficient supply of carbon for subsequent intergranular precipitation. Thus, additional thermal treatments may not significantly modify the microstructure or SCC resistance. Maximum improvement in SCC resistance is observed for alloys with a semi-continuous array of IG carbides. This implies that

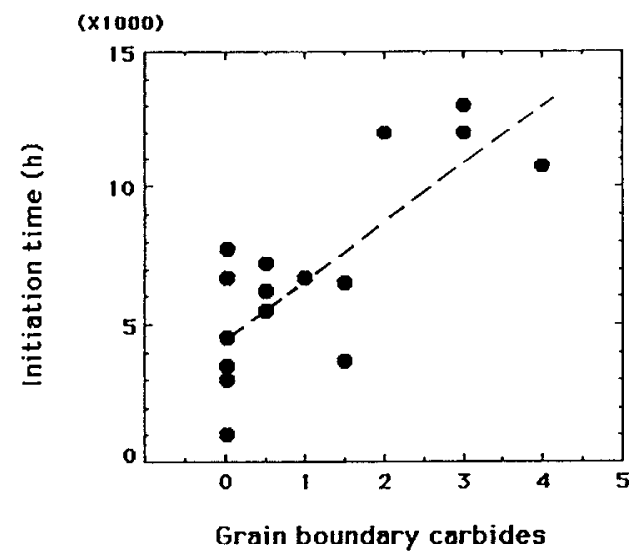

Fig. 8. Influence of grain boundary carbides $(0=$ no carbides; $5=$ complete coverage with carbides) on the crack initiation time of alloy 600 in RUB specimens immersed in high-purity water with $50 \mathrm{ml} \mathrm{H}_{2} / \mathrm{kg} \mathrm{H}_{2} \mathrm{O}$ at $365^{\circ} \mathrm{C}$ (from ref. [56]).

SCC resistance is dependent on the morphology and distribution of IG carbide precipitates. However, the mechanism by which this occurs remains open to some debate.

Considerable interest has been focused on the role of the chromium-rich carbides themselves as the activators of IGSCC by both chemical and mechanical mechanisms. Several studies [55-57] have reported correlations between high grain boundary carbide coverage (density) and increased IG cracking resistance, Fig. 8. In two instances, the reverse has been true. However, these occurred in tests in $25 \mathrm{M} \mathrm{NaOH}$ at $140^{\circ} \mathrm{C}$ [58] and in oxygenated water at $350^{\circ} \mathrm{C}$ [59], in which the enhanced IGSCC susceptibility was attributed to preferential dissolution of the grain boundary carbides. Hence, the advantages or disadvantages of semi-continuous IG carbides with respect to IGSCC is highly dependent on the environment.

\section{Chromium depletion}

Precipitation of chromium-rich carbides at grain boundaries in alloy 600 result in the formation of a chromium-depleted region for certain time-temperature conditions. Because of the low carbon solubility and fast chromium diffusion, depletion occurs much more rapidly (i.e., at shorter times at temperatures between 500 and $750^{\circ} \mathrm{C}$, and for faster cooling rates from higher temperatures) in alloy 600 than in unstabilized austenitic stainless steels. Depending upon the temperature at which they form and grow, isolated carbide precipitates can produce localized regions of chromium depletion which is not continuous along boundaries. The relatively high diffusivity of chromium in alloy 600 enables the chromium content to be re- 
plenished at interfaces during heat treatments at temperatures greater that $650^{\circ} \mathrm{C}$. As a result, thermal treatment can produce a desensitized microstructure (i.e., semi-continuous carbide precipitation without chromium depletion). The exact time-temperature dependence of chromium depletion and desensitization will again be dependent on the material bulk composition and prior thermomechanical history.

When a chromium carbide begins to precipitate at the grain boundary, paraequilibrium is established between the chromium in the carbide and the chromium in the matrix. Once precipitation has begun, the value of chromium in equilibrium with the carbide will change (hence the term paraequilibrium) because the activities of the chromium and carbon change as they are consumed by the growing carbide. Thus, the amount of chromium in equilibrium with the carbide increases with time. The resulting chromium depletion profile represents a complex interplay between changing equilibrium conditions at the carbide-matrix interface and the kinetics supplying chromium and carbon to the carbide. Fig. 9 shows the dependence of the paraequilibrium grain boundary chromium concentration on the temperature and the alloy carbon content of alloy 600 versus that for an austenitic stainless steel. Decreasing temperatures or increasing carbon contents will tend to increase the extent of chromium depletion.

Although chromium depletion can be present in mill-annealed tubing, and may be increased during long exposures at steam generator operating temperatures, depletion is not a controlling factor in the SCC

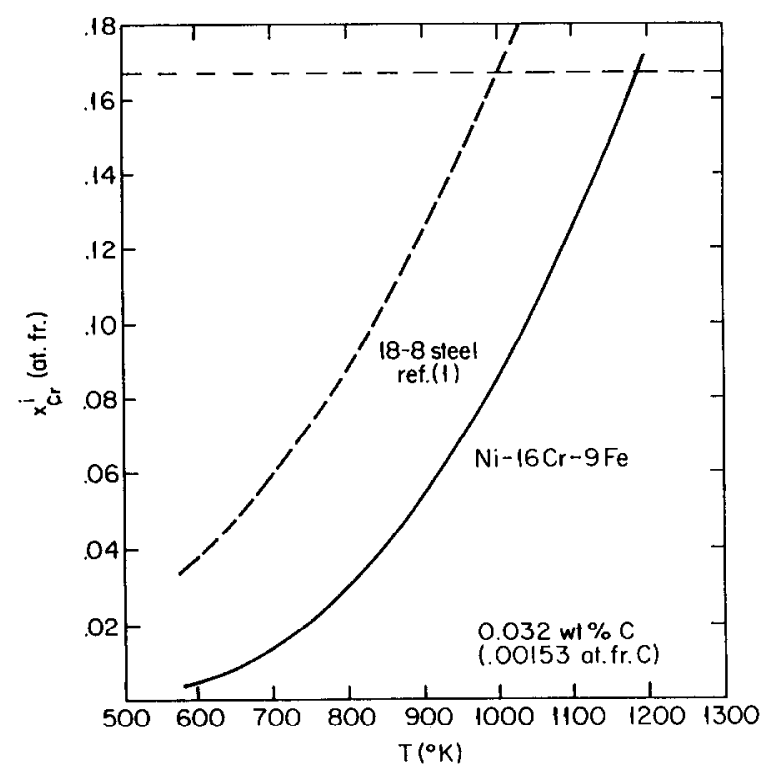

Fig. 9. Equilibrium chromium concentration at the carbidematrix interface of $\mathrm{Ni}-16 \mathrm{Cr}-9 \mathrm{Fe}-0.03 \mathrm{C}$, and $18-8$ stainless steel as a function of temperature. of alloy 600 in high-temperature deaerated water or caustic environments. Chromium depletion does appear to accelerate cracking in oxygenated water or in low-temperature acidic environments (Fig. 7), but the opposite is more consistent with the data for deaerated water tests and mixed results have been obtained for caustic environments. Since it is difficult to produce significant chromium depletion without semi-continuous carbide precipitation, the effect of chromium depletion on SCC resistance has not been isolated. If chromium depletion is detrimental to primary-side IGSCC, its effect appears to be minor compared to the beneficial effect of IG carbides.

\section{Grain boundary segregation}

As for austenitic stainless steels, phosphorus is the primary segregant to grain boundaries in alloy 600 . Grain boundary phosphorus segregation increases sharply with decreasing temperature until the solubility limit is exceeded (i.e., at about $700^{\circ} \mathrm{C}$ for a $100 \mathrm{ppm}$ heat). Below this temperature the amount of phosphorus available to segregate decreases with decreasing temperature, and segregation increases at a much slower rate as illustrated in Fig. 4. Phosphorus levels at grain boundaries in MA commercial alloy 600 are typically on the order of several atomic percent and increase to $\sim 10$ at $\%$ after several hours at $700^{\circ} \mathrm{C}$. There is no indication that these levels of phosphorus segregation promote IGSCC in high-temperature water. In fact, recent evidence supports a beneficial cffect of grain boundary $\mathrm{P}$ in high purity $\mathrm{Ni}-\mathrm{Cr}-\mathrm{Fe}$ alloys (without grain boundary carbides or chromium depletion) tested in $360^{\circ} \mathrm{C}$ water [60]. Very little additional information is available concerning the influence of phosphorus segregation without the presence of GB chromium carbides. However, phosphorus-induced IG cracking is observed at lower temperatures in various nickel-base alloys when hydrogen is available [61].

Several other impurities identified at the grain boundaries of alloy 600 include boron, sulfur, nitrogen and titanium. Grain boundary segregation of boron and sulfur has been observed, even when bulk contents are only several parts per million. Boron may be particularly important since it is often observed at grain boundaries of mill-annealed specimens [62]. However, boron segregation has not been shown to induce IG corrosion or SCC. Since low levels of boron retard chromium carbide precipitation and higher levels accelerate precipitation, boron may influence SCC through its effect on IG chromium carbide formation kinetics [61].

Sulfur has not been shown to consistently segregate to grain boundaries in alloy 600 due to the presence of sulfide formers such as magnesium, calcium and tita- 
nium. Significant segregation has only been documented in samples after extremely high-temperature anneals $\left(>1300^{\circ} \mathrm{C}\right)$ where sulfur is released from preexisting inclusions and is able to segregate to grain boundaries. Although sulfur has been proposed to play a role in primary-side IGSCC, it is unlikely based on the limited segregation that occurs in alloy 600 tubing under normal processing and fabrication conditions. However, sulfur strongly segregates in nickel alloys (when available in solution) and is a potent embrittling element at low and high temperatures. It is interesting to note that sulfur does not thermally segregate in low-alloy steels, but does enrich boundaries under creep conditions promoting IG embrittlement.
One alloying element not normally discussed as a segregant in alloy 600 is carbon. Its behavior in certain alloys is believed to be similar to boron and nitrogen, i.e., increases IG cohesive energy and improves resistance to hydrogen embrittlement. Unfortunately, very little direct evidence is available for alloy 600. Carbon is known to strongly segregate in commercial-purity nickel leading to graphite precipitation at grain boundaries [63]. It also segregates to boundaries in alloy 600 during nucleation and growth of chromium-carbide precipitates. In the solution-annealed (SA) and MA conditions, it is certain that some degree of interfacial carbon enrichment is present. Recent experiments [64] have established a correlation between grain boundary

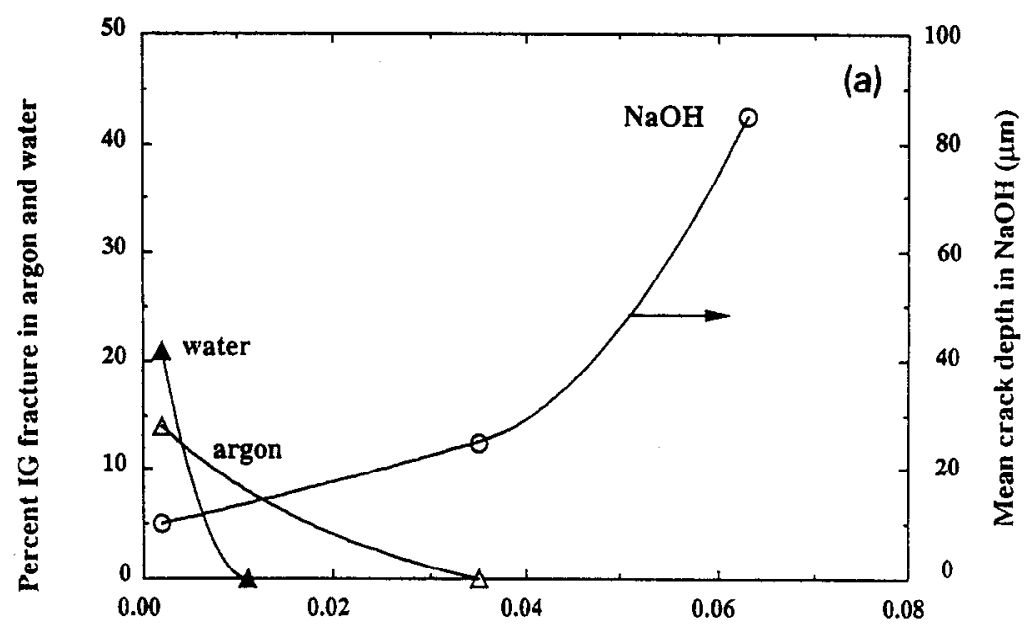

Bulk carbon concentration (wt\%)

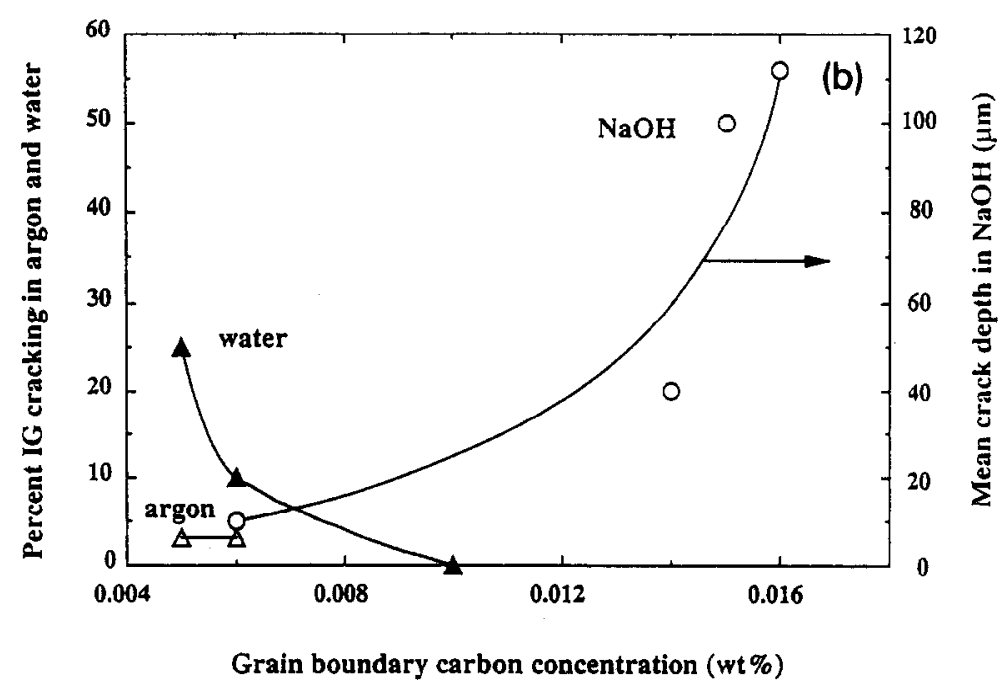

Fig. 10. Effect of carbon concentration on IG cracking of alluy 600 in caustic at $140^{\circ} \mathrm{C}$, and in argon and water at $360^{\circ} \mathrm{C}$ : (a) Bulk carbon concentration and (b) grain boundary carbon concentration resulting from chromium carbide precipitation. 
carbon segregation and IGSCC resistance in $360^{\circ} \mathrm{C}$ water. As in the case of chromium carbides, the effect is strongly dependent on environment, and carbon segregation has been shown to result in more severe IGSCC in $140^{\circ} \mathrm{C} \mathrm{NaOH}$, Fig. 10 . However, inherent difficulties in grain boundary fracture and carbon composition analysis (contamination) have restricted a complete quantitative assessment. Significant segregation of elemental carbon may also be limited by competitive phosphorus segregation. Interstitials such as carbon, boron and nitrogen may be the only elements (besides hydrogen) with reasonable mobility at $\sim 300^{\circ} \mathrm{C}$ and may interact with the dynamic effects occuring at GBs at this temperature.

\section{Interfacial deformation and creep}

The observation that a semi-continuous distribution of IG carbide precipitates improves SCC resistance suggests that the carbides may be affecting grain boundary mechanical behavior. Interfacial deformation and cracking is directly influenced by the presence of carbides. A semi-continuous distribution of carbides can promote IG fracture at low temperatures and IG creep cavities at elevated temperatures. However, direct studies of interfacial deformation processes have been limited. Bruemmer and Henager [65] evaluated deformation characteristics at $300^{\circ} \mathrm{C}$ and demonstrated that IG carbides control dislocation activity at low strains. Grain boundary carbides were proposed to be effective dislocation sources because they block dislocation movement within the boundary during sliding, produce a large local stress concentrations, and may have better access to matrix slip planes for easy emission into the lattice. This allows grain boundary precipitates to emit dislocations at lower macrostresses and strains and also to continue to operate against higher back stresses than other sources.

More recent results have indicated that bulk creep deformation plays an important role in the susceptibility of alloy 600 to IGSCC and explain the increased cracking resistance of high-chromium alloy 690 . Research by Was and co-workers $[64,66]$ has demonstrated that increasing the bulk carbon or chromium content in a high-purity $\mathrm{Ni}-\mathrm{Cr}-\mathrm{Fe}$ alloy sharply decreases the creep rate and \% IGSCC. For example, carbon in solution was found to alter the matrix and grain boundary dislocation substructure and inhibit the formation of intergranular void formation. The hightemperature water environment has been shown to accelerate the creep rate in alloy 600 over that in air $[66,67]$. This suggests that hydrogen adsorption into the metal may be enhancing bulk dislocation activity, or the water environment degrades any benefit of the surface film on resisting creep deformation. If creep plays an important role in the IGSCC, it is likely that grain boundary sliding (GBS) is an essential part of the cracking mechanism. Grain boundary sliding is discussed below in relation to the microstructure and microchemistry of alloy 600 .

Grain boundary sliding does not typically become a significant deformation mode at temperatures above $\sim 0.4$ of the melting temperature. Interestingly, this is approximately the temperature $\left(\sim 360^{\circ} \mathrm{C}\right)$ where IGSCC is reproduced in the laboratory and where sliding has been observed in mill-annealed alloy 600 tubing. It is well founded that sliding contributes to the overall strain during dislocation creep and is necessary for diffusion creep [68-70]. One way in which sliding can occur is by the dissociation of a matrix dislocation into either perfect or partial grain-bounary dislocations (GBD). These dissociation reactions minimize the grain boundary energy and can rearrange the local structure of the grain boundary. This process can explain many aspects of GBS [71] including:

- A threshold stress is often observed for GBS analogous to matrix slip since a friction stress must be overcome. IG precipitates (carbides) are effective barriers to GBD movement and increase the observed threshold stress.

- Grain boundary hardening results during dislocation creep primarily due to the pile-up of lattice dislocations. Steps in the boundary are created by impingement of matrix dislocations and impede interfacial dislocation movement.

- A relationship commonly exists between matrix strain and GBS strain, since boundary sources are critical in the bulk deformation process.

- Grain boundary migration often accompanies GBS because interfacial dislocations (depending on the local Burgers vectors and boundary plane) can produce both events simultaneously.

- The activation energy for GBS is typically between the extremes for $\mathrm{GB}$ and matrix diffusion resulting from the mechanisms controlling the rate of sliding, i.e., interfacial diffusion required for the climb of boundary dislocations or matrix diffusion required for accommodation processes in the adjacent grains. Diffusional mass transport along grain boundaries controls many metallurgical processes under certain stress-temperature conditions including diffusional creep. [72] Fast diffusion in the boundary plane appears to occur by a vacancy mechanism with atoms jumping between various sites in the boundary plane. The strong influence of structure and solute segregation on interfacial diffusivity may be partially explained by differences in the core sites. Specific impurity segregants such as boron in iron and sulfur in copper have been shown to have very large effects on grain boundary diffusivity. [73] It is possible to increase or decrease interfacial diffusivity by modifying the boundary com- 
position. Very little is known concerning segregant (i.e., carbon, nitrogen, boron and phosphorus) effects on interfacial diffusivity or GBS in alloy 600. Local hydrogen effects must also be considered. Hydrogenenhanced plasticity definitely occurs and may play a dominant role in promoting GBS through its effect on the climb of GBDs and on local matrix accommodation processes. Second-phase particles obstruct GBD migration and restrict GBS until higher local stresses are produced or tests are performed at higher temperatures.

Creep cavities can nucleate at stress concentrations which arise at inhomogeneities in sliding grain boundaries and can be assisted by a vacancy condensation (diffusional) mechanism [68,72]. Solute segregation effects noted above can control the nucleation and growth of grain boundary cavities in several ways. Segregants which decrease cohesion at the grain-to-grain or particle-matrix interface will reduce the stress required for wedge cracks or cavities to form. In addition, segregation at the newly-formed cavity may reduce its surface energy, and thereby reduce the critical size for a stable cavity. Cavity nucleation will also be determined by grain boundary sliding which again is dependent on local composition. The largest influence on cavity growth will stem from segregation effects on diffusional mass transport along grain boundaries and on newly formed surfaces.

The resistance of a material to creep embrittlement depends on the mechanisms of interfacial deformation, cavity nucleation and cavity growth. Grain boundary chemistry resulting from segregation events before or during deformation must be considered. The enrich- ment of certain impurity elements has been shown to increase the susceptibility to creep and stress-relief embrittlement [73]. Solute segregation can modify grain, and particle-matrix, interface cohesive energies, influence cavity surface energies and control the resultant mechanical properties. However, direct investigations linking solute segregation to cavity nucleation and growth have been limited, and no research has addressed the complexities of the particle-matrix interface nor the interfacial deformation processes leading to cavity nucleation.

An additional consideration is that of grain boundary structure. It is well established [74-76] that deformation and strength are strong properties of the orientation relationship between grains, or the misorientation of grain boundaries. The coincident site lattice (CSL) model of grain boundary structure classifies grain boundaries into one of three categories based on the relative misorientation between the grains adjacent at the boundaries. Low-angle boundaries (LABs) have misorientation angles of up to $15^{\circ}$. Coincident site lattice boundaries (CSLBs) are defined in terms of the degree of overlap (coincidence) of the interpenetrating lattices of adjacent grains. All other boundaries are considered as general high-angle boundaries. CSL and LABs constitute 12 to $20 \%$ of the grain boundaries of most annealed alloys. Thermomechanical processing can increase this fraction to nearly $50 \%$. CERT and creep experiments of CSLB-enhanced samples show more resistant to IG cracking in water, and a reduced creep rate in argon at $360^{\circ} \mathrm{C}$, as documented in Fig. 11 $[67,77]$. Although the mechanism is not precisely known, the beneficial effect of LABs and CSLBs is believed to
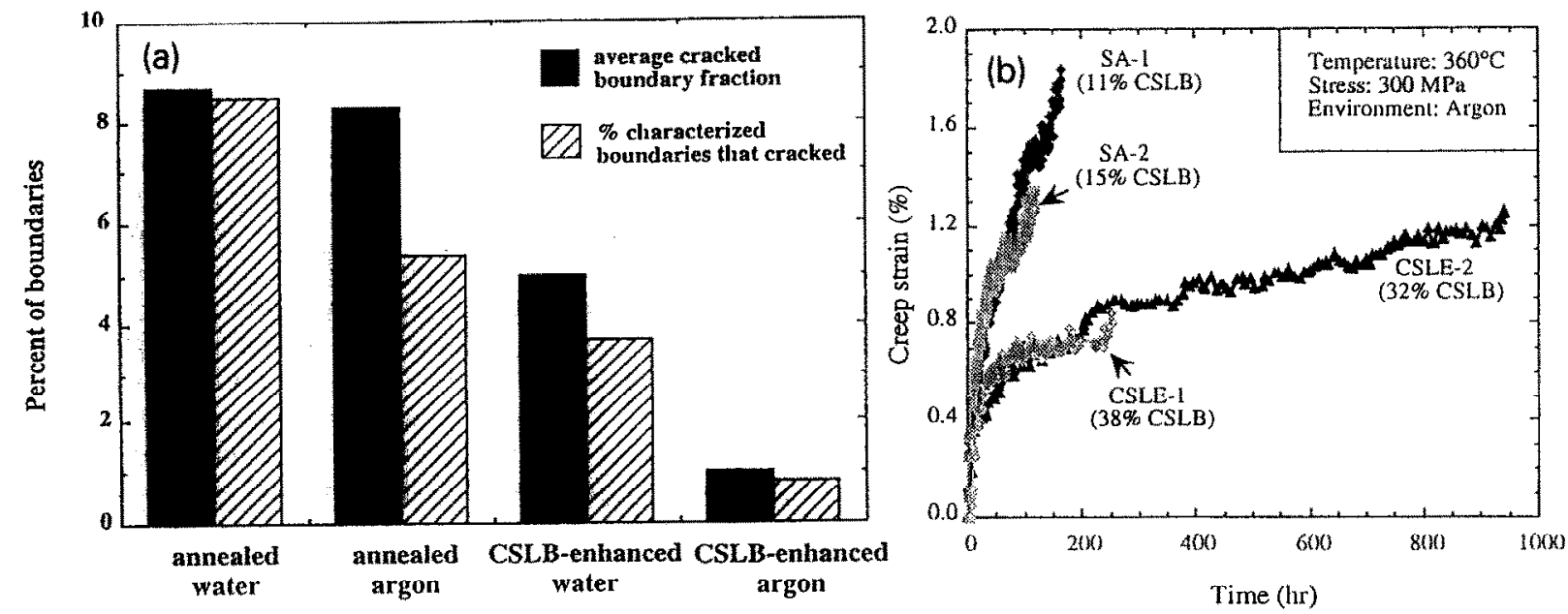

Fig. 11. Grain boundary structure effects on IGSCC and creep. (a) Comparison between cracked boundary fractions and the percentages of characterized boundaries that cracked, and (b) constant load creep curves of coarse-grain $\mathrm{Ni}-16 \mathrm{Cr}-9 \mathrm{Fe}$ as a function of percentage CSL boundaries in $360^{\circ} \mathrm{C}$ argon at $300 \mathrm{MPa}[67,77]$. 
be due to their ability to induce slip in neighboring grains by cither transmitting or absorbing and re-emitting lattice dislocations, thereby reducing grain boundary stresses and the propensity for GBS or crack formation. This presents the potential for controlling deformation and cracking through grain boundary structure.

The general concepts discussed above for GBS do not answer the specific questions concerning IGSCC of alloy 600 in deaerated high-temperature water. Based on the information at hand, it appears that resistance to GBS scales consistently with resistance to IGSCC. Hydrogen could reduce the threshold stress for GBD movement and enable sliding to occur at lower temperatures. Crack propagation could result from small cavity formation immediately ahead of the crack tip at boundary inhomogeneities such as slip step. If this is the case, segregants may play an important role in the formation of stable cavities. Mobile elements within the boundary may enrich and stabilize the newly created surface produced during sliding.

\section{IGSCC mechanisms and remedial actions}

Specific grain boundary microstructural, microchemical and mechanical issues related to the IGSCC of alloy 600 in high-temperature water have been discussed. Interfacial carbide precipitation, chromium depletion, impurity segregation and local deformation characteristics are examined and related to IGSCC behavior. Grain boundary carbide precipitation has a dominant effect improving IGSCC resistance, while chromium depletion and impurity segregation have secondary effects at most. The key to cracking susceptibility remains focussed on the local deformation behavior at grain boundaries with recent results indicating an important effect of matrix and interfacial creep processes. Hydrogen may be a necessary component for crack propagation either by an interfacial decohesion or by an enhanced plasticity mechanism. Detailed experimentation and modeling is needed to elucidate the complex interactions among grain boundary deformation, solute segregation, hydrogen and IG crack propagation.

Because basic understanding of the mechanisms controlling steam generator tube cracking have not been established, the confidence level for effective material remedial actions is not as high for alloy 600 tubing SCC as it is for SS pipe cracking. More recent alloy 600 steam generator tubes have been thermally treated to ensure a high density of semi-continuous grain boundary carbides, while the next generation of tubing will probably be thermally-treated alloy 690 . However, many questions remain concerning the longterm behavior of these replacement materials. Other remedial actions have been shown to have a positive effect [47]. Specific improvements in behavior have resulted from reducing tensile stresses by some form of in-situ heat treatment, or by peening the tube surface to produce compressive stresses. Environmental corrective actions are a bit more difficult for the primaryside and have been limited to reducing the coolant temperature in the U-bend regions where possible.

\section{Conclusions}

The two examples reviewed illustrate the significant differences in the microstructural and microchemical mechanisms that can control IGSCC in selected LWR components. Specific aspects of grain boundaries including precipitation, alloying element redistribution, impurity segregation and interfacial deformation in stainless alloys are discussed in relation to BWR pipe cracking and primary-side SCC of PWR steam generator tubing. IGSCC of austenitic SS piping is a well-understood process, metallurgically controlled by the extent of chromium depletion at internal interfaces. Cracking susceptibility can be sharply reduced by the elimination of this localized depleted region. Many other microstructural and microchemical changes occur at SS grain boundaries, but they appear to have only a comparatively small effect on IGSCC in BWR environments. Although grain boundary chromium depletion can be produced in alloy 600 steam generator tubing, it appears to have little effect on IGSCC in primary-water environments. Only IG carbides have been shown to have a strong beneficial effect on cracking resistance. The mechanisms of the cracking process remain poorly understood. Much of the current emphasis is focussed on bulk and interfacial deformation, and their influence on cracking mechanics. A combination of basic and applied research has led to a functional solution to BWR pipe cracking, while this research is still required to address long-term solutions for PWR steam generator tubing.

\section{Acknowledgements}

Support from the Materials Sciences Branch of the Office of Basic Energy Sciences, US Department of Energy under contract DE-AC06-76RLO 1830 and under Grants DE-FG02-93ER-12130 and DE-FG0285ER45184 is gratefully acknowledged.

\section{References}

[1] R.L. Jones, G.M. Gordon and G.H. Neils, Proc. 4th Int. Symp. on Environmental Degradation of Materials in Nuclear Power Systems - Water Reactors (National As- 
sociation of Corrosion Engineers, Houston, TX, 1990) p. $1-1$.

[2] S.J. Green, in Corrosion in the Nuclear Power Industry, ed. J.C. Danko, Metals Handbook, vol. 13: Corrosion (ASM International, Metals Park, OH, 1987) p. 937.

[3] B.M. Gordon and G.M. Gordon, ibid. Ref. [2], p. 927.

[4] S.M. Bruemmer, in Grain Boundary Chemistry and Intergranular Fracture, eds. G.S. Was and S.M. Bruemmer (Trans Tech Publications, Switzerland, 1989) p. 309.

[5] V. Cihal, Intergranular Corrosion of Steels and Alloys, Materials Science Monograph No. 18 (Elsevier, New York, 1984).

[6] R. Strickler and A. Vinckier, Trans. ASM 54 (1961) 362.

[7] E.C. Bain, R.H. Aborn and J.J.B. Rutherford, Trans. Am. Soc. Steel Treating 21 (1933) 481.

[8] J.B. Lumsden and P.J. Stocker, Scripta Metall. 15 (1981) 1295.

[9] C.L. Briant, Scripta Metall. 21 (1987) 77.

[10] L. Karlsson and H. Norden, Acta Metall. 36(1) (1988) 13.

[11] A.W. James and C.M. Shepherd, Mater. Sci. Technol. 5 (1989) 33.

See also S. Dumbill, R.M. Boothby and T.M. Williams, Mater. Sci. Technol. 7 (1991) 385.

[12] A. Joshi and D.F. Stein, Corr. J. 28 (1972) 321.

[13] K. Osozawa and H.J. Engell, Corr. Sci. 6 (1966) 389.

[14] C.S. Tedmon, Jr., D.A. Vermilyea and J.H. Rosolowski, J. Electrochem. Soc. 118 (1971) 192.

[15] W.J. Shack, Environmentally Assisted Cracking in Light Water Reactors, US Nuclear Regulatory Commission, NUREG/CR-3806 (1984) and NUREG/CR-4287 (1985).

[16] M. Fox, J. Mater. Energy Syst. 1 (1979) 3.

[17] F.A. Nichols, Mechanistic Aspects of Stress Corrosion Cracking of 304 Stainless Steel in LWR Service, US Nuclear Regulatory Commission, NUREG/CR-3220 (1983).

[18] F.P. Ford, D.F. Taylor and M.E. Indig, Mechanisms of Environmental Cracking in Systems Peculiar to the Power Generation Industry, Electric Power Research Institute, Palo Alto, CA, EPRI-NP-2587 (1982).

[19] R.L. Cowan and G.M. Gordon, Proc. Stress Corrosion Cracking and Hydrogen Embrittlement of Iron-Base Alloys (National Association of Corrosion Engineers, Houston, TX, 1977) p. 1025.

[20] S. Szklarska-Smialowska and G. Cragnolino, Corr. J. 36 (1980) 653.

[21] M.E. Indig, B.M. Gordon, R.B. Davis and J.E. Weber, Proc. 2nd Int. Symp. on Environmental Degradation of Materials in Nuclear Power Systems - Water Reactors (American Nuclear Society, Lagrange Park, IL, 1986) p. 411.

[22] B. Rosborg and A. Molander, ibid. Ref. [21], p. 419.

[23] D.D. Macdonald and G. Cragnolino, ibid. Ref. [21], p. 426.

[24] K. Osozawa, K. Bohnenkampf and H.J. Engell, Corr. Sci. 6 (1966) 421.

[25] Aho-Mantila and H. Hanninen, Proc. 9th Scandinavian Corrosion Congress, Helsinki, 1984, p. 61.

[26] A. Desestret, Contributions a'l'Etude de la Transpassivite des Aciers Inoxydables, Ph.D. Dissertation, University of Paris, 1964.
[27] J.S. Armijo, Corr. J., 24 (1968) 24.

See also J.S. Armijo, Grain Boundary Studies of Austenitic Stainless Steels, General Electric Company, GEAP-5503, (1967).

[28] G.M. Gordon, ibid. Ref. [19], p. 843.

[29] B. Vyas and H. Isaacs, Proc. IG Corosion of Stainless Steels, ed. R.F. Steigerwald, ASTM-STP 656 (American Society for Testing of Materials, Philadelphia, 1978) p. 133.

[30] S.M. Bruemmer and L.A. Charlot, Corr. J. 44 (1987) 427.

[31] I. Oleford, Mater. Sci. Eng. 92 (1980) 161.

[32] A.E. Yaniv, J.B. Lumsden and R.W. Staehle, J. Electrochem. Soc. 124 (1979) 490.

[33] C.L. Briant and E.L. Hall, Corr. J. 43 (1986) 522.

[34] S.M. Bruemmer, Corr. J. 44 (1988) 364.

[35] G.S. Was and V.B. Rajan, Metall. Trans. 18A (1987) 1313.

[36] D.B. Wells, J. Stewart, A.W. Herbert, P.M. Scott and D.E. Williams, The Use of Percolation Theory to Predict the Probability of Failure of Sensitised, Austenitic Stainless Steels by Intergranular Stress Corrosion Cracking, Harwell Laboratory, Oxfordshire, England AERER12903 (1987).

[37] H. Okada, S. Abe, M. Kojima and Y. Hosoi, Proc. 7th Int. Congress on Metallic Corrosion, ABRACO, Rio de Janero, 1978.

[38] A.J. Jacobs, R.E. Clausing, L. Heatherly and R.M. Kruger, Proc. 14th Int. Symp. on Effects of Radiation on Materials, Andover, MD (American Society for Testing of Materials, 1988).

[39] R.H. Jones, ibid. Ref. [21], p. 173.

[40] P.L. Andresen and C.L. Briant, Proc. 3rd Int. Sym. Environmental Degradation of Materials in Nuclear Power Systems - Water Reactors, eds. G.J. Theus and J.R. Weeks, (The Metallurgical Society, Warrendale, PA, 1988) p. 371.

[41] P.L. Andresen, Proc. Corrosion/87 (National Association of Corrosion Engineers, Houston, TX, 1987) paper 84.

[42] R.H. Jones, M.J. Danielson, S.M. Bruemmer, D.R. Baer and M.T. Thomas, Proc. Embrittlement by the Localized Environment, ed. R.P. Gangloff (The Metallurgical Society, Warrentown, PA, 1984) p. 419.

[43] E.P. Butler and M.G. Burke, Proc. Int. Conf. on SolidState Phase Transformations, eds. H.I. Aaronson, D.E. Laughlin, R.F. Sekarda and C.M. Wayman (The Metallurgical Society, Warrentown, PA, 1981) p. 775.

[44] M.G. Lackey and F.J. Humphreys, Proc. 3rd Int. Conf. on Effects of Hydrogen on Behavior of Materials, eds. I.M. Bernstein and A.W. Thompson, (The Metallurgical Society, Warrentown, PA, 1980) p. 665.

[45] C.L. Briant, Metall. Trans. 9A (1978) 731.

[46] H.E. Hanninen, T. Purra and J. Hakela, ibid. Ref. [37], p. 441.

[47] R.L. Jones, Corrosion Experience in US. Light Water Reactors - A NACE 50th Anniversary Perspective, Corrosion/93 (National Association of Corrosion Engineers, Houston, TX, 1993) paper 168.

[48] P. Saint-Paul and G. Slama, Proc. 5th Int. Sym. on Environmental Degradation of Materials in Nuclear 
Power Systems - Water Reactors, eds. E.P. Simonen, D. Cubicciotti and R. Gold (American Nuclear Society, La Grange Park, IL, 1992) p. 39.

[49] S.M. Bruemmer, Proc. Alloy 600 Experts Meeting, Arlie, VA (Electric Power Research Institute, Palo Alto, CA, 1993).

[50] G.S. Was, ibid. Ref. [4], p. 335.

[51] E.L. Hall and C.L. Briant, Metall. Trans. A. 61A (1985) 1225.

[52] G.S. Was and R.M. Kruger, Acta Metall. 33 (1985) 841.

[53] S.M. Bruemmer, Microstructural Effects on Microdeformation and Primary-Side Stress Corrosion Cracking of Alloy 600 Tubing, Electric Power Research Institute, Palo Alto, CA, EPRI NP-5192 (1987).

[54] G.P. Airey, A.R. Vaia, N. Pessall and R.G. Aspden, J. Metals (1981) 29.

[55] K. Norring, J. Engstrom and P. Norberg, ibid. Ref. [40], p. 587.

[56] G.P. Airey, Corr. J. 35 (1989) 129.

[57] K. Norring, J. Engström and H. Törnblom, ibid. Ref. [1], p. 12-1.

[58] X. Liu, J. Shao, G. Cragnolino and D.D. Macdonald, Proc. Corrosion of Nickel-Base Alloys, ed. R.C. Scarberry (American Society of Metals, Metals Park, OH, 1985) p. 211

[59] R.B. Rebak, Z. Xia and Z. Szklarska-Smialowska, Corrosion 49 (1993) 867.

[60] J.K. Sung and G.S. Was, Corrosion 47 (1991) 824.

[61] R.H. Jones and S.M. Bruemmer, Proc. Environment-Induced Cracking of Metals, eds. R. Gangloff and M.B. Ives (National Association of Corrosion Engineers, 1989) p. 287.
[62] G.P. Airey, Metallography 13 (1980) 21.

[63] T.S.F. Lee and R.M. Latanision, Metall. Trans. 18A (1987) 1653.

[64] G.S. Was, Proc. Parkin's Symp. on Fundamental Aspects of Stress Corrosion Cracking, eds. S.M. Bruemmer, E.I. Meletis, R.H. Jones, W.W. Gerbrich, F.P. Ford and R.W. Staehle (The Minerals, Metals and Materials Society, 1992) p. 371.

[65] S.M. Bruemmer and C.H. Henager, Jr., Corr. J. 44 (1988) 782.

[66] V. Thaveeprungsriporn, T. Angeliu, D. Paraventi, J. Hertzberg and G.S. Was, Proc. 6th Int. Symp. on Environmental Degradation of Materials in Nuclear Power Systems - Water Reactors, Minerals, Metals \& Materials Society, San Diego, CA, August 1993, Session VIII.

[67] J.M. Boursier, T. Magnin, R. Rios, D. Noel and F. Vaillant, ibid. Ref. [66], Session XIII.

[68] G.L. Dunlop and J.-O. Nilsson, Mater. Sci. Eng. 42 (1980) 273.

[69] G.B. Gibbs, Mem. Sci. Rev. Metall. 62 (1965) 775.

[70] R. Raj and M.F. Ashby, Metall. Trans. 2 (1971) 1113.

[71] R.C. Pond, D.A. Smith and P.W.J. Southerden, Philos. Mag. A37 (1978) 27.

[72] R.W. Balluffi, Metall. Trans. 13A (1982).

[73] E.D. Hondros and M.P. Seah, Int. Metals Rev. 222 (1977) 262

[74] T. Watanabe, Mater. Sci. Eng. A166 (1993) 11.

[75] L.C. Lim and T. Watanabe, Acta Metall. 38 (1990) 2507.

[76] H. Kokawa, T. Watanabe and S. Karashima, Philos. Mag. A44 (1981) 1239.

[77] D.C. Crawford and G.S. Was, Metall. Trans. 23A (1992) 1195. 